Published in Corporate Social Responsibility and Environmental Management (2018), 25 (4), 441-456. DOI: 10.1002/csr.1471 ISNN: 1535-3966.

\title{
Sustainable development through CSR in human resource management practices: the effects of the economic crisis on job quality
}

\section{Esther Martinez-Garcia ${ }^{1}$, Joan Sorribes $^{2}$, Dolors Celma ${ }^{3}$}

1. Esther Martinez- Garcia. Department of Economics \& Research group TRIP and INSETUR. University of Girona. Plaça Ferrater Mora, 1. 17004 Girona, Spain esther.martinez@udg.edu Tel. Spain, +34 972419719

2. Joan Sorribes. Department of Economics \& Research group TRIP and INSETUR. University of Girona. Plaça Ferrater Mora, 1. 17004 Girona, Spain. joan.sorribes@udg.edu

3. Dolors Celma. Department of Business and Management. Tecnocampus Universitat Pompeu Fabra. mdcelma@tecnocampus.cat

\begin{abstract}
This article focuses on sustainable development and human resource management (HRM). It analyses the effects of the economic crisis on CSR in the management of employees, its determinants and also depicts a map of job quality for employees in Spain. Results show that the crisis has not changed the overall pattern or map; neither the characteristics of the firm, of the employee and of the job, that determine that map. Results also point to the fact that employees in the lower end of CSR in HRM practices have been the most affected by hard cost-containment measures applied by firms, such as dismissals. Around one third of employees have low job quality in nearly all the dimensions analysed; while two thirds have higher job quality, but with variability among dimensions. The analysis is conducted for the years 2006-2010, hence comprising precrisis and amid the crisis years. Cross-section repeated samples of employees are used,
\end{abstract}


from the Quality of Working Life Survey, which allow to study the evolution of HRM and CSR.

Key words: Corporate social responsibility, sustainable development, human resource management, economic and financial crisis, job quality 


\section{Introduction}

The financial and economic crisis has had very severe consequences in the labour markets in European countries. The most visible effects have been the destruction of large number of jobs and the generation of high unemployment rates. Many surviving firms applied hard labour cost-containment measures, such as employee outsourcing, replacement of full-time contracts with part-time ones and replacement of permanent by non-permanent contracts; and softer measures, as reduction of paid overtime hours and overtime rates. As a result, job quality in Europe declined (European Commission, 2011), contributing to what some authors already observed in the years previous to the crisis (Greenan et al., 2014). For its part, in some countries, especially Mediterranean countries affected by large public deficits and debt, governmental labour regulations to cope with the crisis focussed mainly on sustaining employment and generating new jobs; new labour laws and regulations generating poorer quality jobs. All this has happened despite government laws and declarations in favour of corporate social responsibility (CSR) and sustainable economic growth that has employees as one of its key actors (European Commission, 2011; Olcese, 2013; Steurer et al., 2012). Governmental measures and laws have created new forms of job flexicurity, have reduced employee protection from dismissal, have created new and precarious types of job contracts and have reduced the capacity of trade unions' for collective negotiation.

The poor quality of jobs during the crisis has renewed policy attention to job quality (ILO, 2012; OECD, 2014). Job quality is of interest for employees, as the quality of working life is part of life's quality (OECD, 2013). It is also of interest for firms, when a reduction in job quality may generate low employee's morale and engagement and also higher job stress (Cascio, 2012; Guest, 2002 and 2011). It is also important for institutions, governments and firms interested in society's and employees' wellbeing and also in Corporate Social Responsibility (CSR). Employees and job quality is at the core of the internal dimension of CSR, a responsible management of employees (European Commission, 2001 and 2011; UNO's Global Compact, 1999; ISO 26000 on CSR, SA 8000). It refers to employee well-being at work, through the application of HRM practices such as those that permit to conciliate work and family/personal life, an equitable and fair remuneration, participation of the employee in decision-making, the firm providing 
adequate and sufficient information to the employee, good health and safety conditions at work, and non-discrimination.

CSR and responsible employees management is no doubt considered indispensable for countries' sustainable economic development (European Commission, 2011; Olcese, 2013), and can be a source of firms' competitive advantage (Singh \& Srivastav, 2012). Despite a large and growing theoretical and empirical literature on CSR, few studies have focussed on job quality, its distribution among employees and its determinants, and on the effects of the economic crisis (Celma et al., 2014). Many studies on CSR have taken a policy level approach rather than an analysis of CRS practices (Dobers, 2009), and most applied studies have analysed only large firms, small and medium firms having been mostly neglected, while in some European countries, such as Spain, they constitute the majority of firms. Many studies on CSR have taken information from external sources, such as firms' sustainability and CSR reports, or from firms' managers, while the perspective of the employee has been mostly neglected. Others take CSR with employees as only one of the various dimensions of analysis (Díaz et al., 2016). While the information provided by those studies is valuable, it does not offer detailed information on CSR in the management of employees and its effects on job quality, how it is distributed among employees, which dimensions of job quality rank better and which worst, and which is the employee's perceived job quality. These issues were tackled in Celma et al. (2014) in their study for Spain. The study showed that in 2007, a year previous to the deepest crisis, employees were grouped into clusters, which were characterised mostly by the types of CSR practices that employees received, rather than by the levels of CSR. However, around one-third of employees were distinguished by low CSR in the HRM practices they received. It was also found that some firms' characteristics, such as their dimension, had an influence on the types of socially responsible practices implemented. In addition, there was evidence that some employees' characteristics and characteristics of the job, were also determinants of the clustering, and hence of the grouping of employees according to CSR in the human management practices received.

By its part, human resource management (HRM) studies on the effects of the economic crisis have not focussed its attention on job quality. One of their most salient results is that a general pattern of firms' HRM strategies and reactions cannot be found; except that 
firms have adopted ad-hoc measures in the management of their human resources, to cope with the immediate challenges posed by the crisis, without following prescriptions from HRM theories (McDonnell \& Burgess, 2013; Teague and Roche, 2014). This adds to the need to further research that offers information on CSR in human resource management and job quality, and especially in recent years, during the crisis.

The purpose of the present article is to add further knowledge on CSR in HRM and job quality by analysing the effects of the crisis. It tackles the questions already posed in Celma et al. (2014), in terms of the analysis of the levels, the scope, the distribution and determinants of CSR in HRM; but here the focus is on the effects of the crisis. For that purpose, contrary to the static nature of Celma's et al. (2014) analysis, the present study uses repeated cross-sections data for the period 2006-2010, which includes years previous and amid the crisis, and hence allows studying the evolution of CSR in HRM.

Accordingly, the main research questions of this article, which have the crisis as its centre, are as follows:

(1) Has the crisis had any effect on the types of responsible human management practices most broadly implemented?;

(2) Has the crisis had any effect in the grouping of employees, according to the level and type of responsible practices -job quality-they receive?

(3) In relation to the determinants of the level and types of responsible practices that firms apply and employees enjoy:

(3.1) Are the characteristics of the firm (size, economic sector in which it operates, etc.) relevant to the CSR in the HRM practices implemented? Are there any differences before and during the crisis?

(3.2) Has the crisis modified the influence of the characteristics of the employee (level of education, gender, etc.), and of the job (type of contract, salary, etc.) on the CSR in the HRM practices that employees' receive?

Information on CSR is obtained from the employees themselves, which provides knowledge that complements previous research on CSR whose main sources of information were external to employees (mainly from managers or firms' reports). 
The article is organized as follows: section 2 reviews previous literature; section 3 describes the characteristics of the survey and the selected sample, as well as the methods of analysis; section 4 presents the results of the empirical analysis; and finally, section 5 includes the discussion and draws the main conclusions of the article.

\section{Literature review}

The literature review here included is organized into three blocks relevant to the research questions of this article: first, previous research and evidence on firms' actions in HRM to adapt to the crisis; secondly, on HRM practices in the job quality sphere and its determinants; and finally on job quality and their recent evolution. It also includes previous evidence on CSR in HRM in Spain and the specific research questions of the present analysis, such as the practices most implemented and the distribution of employees into groups according to CSR in the HRM practices they receive.

\section{Firms actions in HRM to adapt to the crisis}

There is evidence that with the crisis firms have in general, implemented labour costcontainment measures (Gunnigle et al., 2013; McDonnell \& Burgess, 2013; Ryan \& Slevin, 2012) which in turn have generated reductions in job quality (increased job insecurity, lower wages and salaries, precarious jobs, higher work-loads, etc.; Izquierdo \& Lacuesta, 2010; Laborda, 2011; Lahera, 2006; La Caixa, 2013; Muñoz del Bustillo et al., 2011; Prieto et al., 2009; Prosser, 2016). The study by Homs \& Obeso (2009) pointed out that in Spain firms have employed different labour strategies in response to the economic crisis. Mature companies, who prior to the crisis had relatively stable environments, have looked to adapt through salary freezes and/or reductions in salaries or, as a last resort dismissals, and in general cutting in HR investments, while waiting for the situation to improve. A large part of the services sector has taken advantage of the growing job insecurity of a large number of workers to maintain businesses that would not be viable in normal circumstances. Finally, a third option emerges from the idea that the crisis has brought about changes that firms can look upon as new opportunities, making it necessary to focus on developing the human skills that would make their 
exploitation possible; which involves communication programmes and very focused training.

However, not much more is known. One of the most outstanding contributions from the human management literature, is that there is still little knowledge on how firms have adapted their human management practices to the crisis (Shen \& D'Netto, 2012; Teague $\&$ Roche, 2014). There is however, some evidence that measures were ad-hoc, standing off HRM theories (Homs and Obeso, 2009; Teague \& Roche, 2014).

\section{CSR in HRM practices and its determinants}

Most contributions to the determinants of the HRM practices applied by firms come from the HRM literature, within which a minority of studies tackle CSR in HRM. Most of this literature is not focussed on the effects of the crisis, but it is relevant for this article, as it provides information on which determinants should be included in the subsequent empirical analysis and on the qualitative effects of each determinant.

According to the HRM literature, different organizational cultures and firms' characteristics, as well as job and employee characteristics can generate differences in the application of HRM practices. This in turn can generate substantive implications for job quality (Danford et al., 2008; Gallie et al., 2012). One of the areas most analysed recently that is related to firm's culture and HRM are the "high performance" or also called "innovative" HRM practices. Firms oriented towards achieving high involvement and performance from their employees should be more aware of the potentially negative adverse effects of a reduction in job quality, at least in the dimensions related to those innovative practices (team work, training, information sharing, etc.) as they consider employees as a key asset for firm's performance (Appelbaum et al., 2000; Cascio and Boudreau, 2012; Guest, 2002; Homs and Obeso, 2009; Roche et al., 2011). The size of the company can also affect the labour practices that firms apply. Mankelow (2008), Murillo (2008) and Hsu \& Cheng (2012) emphasise that small and large-scale companies have different priorities and motivations, and apply responsible labour practices differently. Large companies may tend to generate more formal working environments and to offer better working conditions (Idson \& Oi, 1999). However, Smith \& Hayton 
(1999) and Sheppeck \& Militello (2000) found that company size did not influence the extent to which some practices were adopted over others. The industry in which the company operates is also a relevant factor to consider. It conditions the company's activity and obviously also its strategy (García et al., 2007), and therefore can also condition its CSR actions with employees when deciding which type of human resource management apply and to what extent. Hofstede (1991) emphasises the importance of the particular industry due to differential characteristics in production processes; Terpstra \& Rozell (1993) observed that HRM practices have a greater effect in service companies (more work-intensive than manufacturing companies). However, inter-industry heterogeneity can also be relevant, as was found by Amossé et al. (2016) in their analysis of job quality differences among Britain and France from 2004 to 2011.

By its part, Boxall (2003) highlights the fact that labour practices are conditioned by activities being segmented so that employees who do more routine work and manufacture a standard product are subject to Taylorist-style labour practices, while more humanistic practices are applied to the segment with more qualified jobs. Different rates of diffusion of innovation and technologies have also contributed to the knowledge on HRM practices, highlighting its contribution to a polarization of job quality in favour of high- qualified workers and less routine jobs (Goos et al., 2010).

National-level institutions can also affect the quality of jobs. For example, Guest (2002) found that the more conventional labour practices generally promoted by unions (such as equal opportunities, prevention of harassment in the workplace and vertical communication) were used more generally by companies, regardless of the industry, than those relating to high-performance practices. In line with Guest's (2002) findings, evidence in Spain shows that, at least in large firms, most widespread business actions for improving job quality were in the areas more regulated by law and most promoted by unions (health and safety at work, training, equal opportunities and internal communication); while measures to help the balance between professional and personal life, such as flexible working hours, were not widely introduced (Aragón \& Rocha, 2004; Instituto de Estudios Laborales, 2006; Media Responsable, 2007). No information is available for small firms, although they constitute the great majority of firms in Spain. By its part, during the crisis, governments' actions towards increasing employment (new laws that facilitate dismissals and cheap and precarious new contracts, and regulations 
that diminished the bargaining power of unions) have contributed to firms' paying less attention to being socially responsible with their employees, generating a reduction in job quality (European Comission, 2011; Laborda, 2011; Merino et al., 2012; Somarriba et al., 2010).

In addition to firms' and job characteristics, and to institutional factors, employee's characteristics may be also relevant of the CSR in the HRM that employees receive. In the work-life/family balance area of HRM practices, Mora \& Ferrer-i-Carbonell (2009) found that there are significant differences among young recent graduates when it comes to working conditions, worse for women in terms of salary, working contract, and discrimination; and concerning employee's nationality, Gamero (2009) draws together empirical evidence for Spain revealing that immigrants tend to be more concentrated in low level occupations and with lower salaries. Finally, Bryson et al. (2016) found that job quality depends on the occupational hierarchy; those in managerial positions enjoying the best job quality.

Job quality: levels, dimensions, and recent evolution

There is a scarcity of recent research on CSR and job quality in Spain, despite it is one of the European countries most affected by the crisis, with unemployment rates above $20 \%$ and where government actions in the labour sphere have been more drastic. Moreover, some of the evidence may appear contradictory. Merino et al. (2012) analysed job quality at the regional level and found that the crisis generated a reduction in job quality in all the Spanish regions. In contrast, the analysis by Díaz-Caho et al. (2016) shows that there was a light increase in job quality between 2005 and 2010 in some dimensions of job quality, such as working conditions and health and safety at work. Since both studies used different measures and indicators of job quality, the opposite results of both studies may be compatible. In the first one, macro-indicators, such as unemployment rates, were included in the analysis. Unemployment grew in that period and therefore job quality measures which include this macro-variable are lower. Moreover, the second study asked employees about their "satisfaction with" different dimensions of job quality. Therefore, although objective parameters of job quality may indicate lower job quality (for example, lower wages), still employees may be equally satisfied with their wage, since satisfaction 
is a psychological result which depends, among others, on expectations. And expectations can be lower in times of crisis. By its part, the studies by Green \& Mostafa (2012) and Green et al. (2013) for European countries show that, in the period 20052010, Spain was among the group of countries with lower levels of job quality, according to surveyed employees. The "physical environment" dimension of job quality was the dimension better ranked. Job quality also experienced a positive evolution during the period of analysis, as did the dimension "work quality" (which is related to raising employee's high performance and includes HRM practices such as training and learning, employee's participation in decisions and task discretion) and the dimension "working time". However, there was also an increase in "work intensity" between 2005 and 2010. These studies did not use the same items as Díaz-Caho et al. (2016) to measure job quality. In addition, questions to employees were of the type "are you exposed at work to noise so loud that you would have to raise your voice to talk to people", instead of asking for "satisfaction with" as in Díaz-Caho et al. (2016). Despite these methodological difference between studies, and its implication for the results obtained in each of them, they have in common that they point out that specific dimensions of job quality improved during the crisis, at least for employees who were still employed in 2010. Finally, in Celma et al. (2014) it was found that in 2007 around one third of employees received HRM practices with low levels of CSR. The remaining two-thirds were nearly equally distributed between a group with higher CSR in HRM practices oriented towards promoting employee's involvement and performance (such as training and information sharing practices) and a group with higher CSR in environmental working conditions. The factors that determined the probability of an employee belonging to one of the three groups were found to be associated to firm's characteristics, employee's characteristics and job characteristics. It is noteworthy that few characteristics had a positive effect in both cases, i.e. in receiving more responsible practices in the environmental working conditions sphere and in the involvement sphere. These were the firm operating in the service sector and characteristics associated to high job positions (high salaries and being a manager). Most of them had various effects, depending on the case. For example, large firms engaged more in HRM for employee involvement, yet the size of the firm did not seem to be relevant for the probability of an employee to receive socially responsible practices in the environmental working conditions sphere. 


\section{Empirical analysis: Materials and methods}

Repeated cross-sections samples of employees in Spain containing information on human resource practices, as well as employee's, firm and job characteristics are used. Information covers a range of years (2006-2010) that includes the years previous to the economic crisis and years where the crisis was deepest. A cluster analysis is performed to find groups of employees characterised by the type and level of responsible practices they receive. The determinants of that grouping, and hence of CSR with employees, is analysed with a multinomial logit model where the groups are the dependent variables. Explanatory variables are firm's, employee's and job's characteristics, as well as a set of dummies for the year of analysis (2006-2010).

The repeated cross-section samples comprise 6,750 employees in Catalonia, Spain. The samples came from the Quality of Work Life Survey (QWLS), which was carried out annually ${ }^{1}$ by the Spanish Ministry of Employment and Social Security and the Catalan Statistical Office. They include information on the characteristics of the employee, of the job and of the firms as well as information on labour practices. Employees were the respondents to the questions. The QWLS samples were obtained with a stratified sampling process carried out in three stages, and include the intersection and aggregation of territorial areas and the size of municipalities. QWL surveys have a series of characteristics that make them particularly useful for our purposes, and which also explains their use in previous studies of job quality and also in the human resource management literature, such as those of Díaz-Caho et al. (2016) and Merino et al. (2012). First, they provide a wide sample of the range of jobs and personal and business situations, as well as the labour practices and hence job quality dimensions applied in the territory under study, which enables for an analysis that goes beyond specific industries, types of firms and employee profiles. This information is also valuable for the present research, as it will allow analysing the factors associated to (determinants) the types of responsible practices and job quality that employees receive. Furthermore, the fact that they are representative of the population of employees means that researchers can generalise the results to a greater degree than when the sample groups are small, which make statistical power and representativeness high. Moreover these national surveys provide information

\footnotetext{
1 The last QWLS includes data for the year 2010; the survey was ceased from then.
} 
according to the perception of the employees themselves. Therefore, the degree and type of job quality practices can be analysed from the point of view of the employee, the stakeholder that is directly affected by them, instead of that of the stakeholder that implements them. Thus, the worker is brought to the central stage (Guest, 2011: 5; Merino et al., 2012).

Descriptive statistics of the variables for CSR in HRM practices and dimensions used in this analysis are found in Table 1, and come from employees' answers. They refer to job quality in the areas of remuneration, training, information and internal communication, health and safety at work, and work/life balance. There are categorical variables (e.g. type of remuneration, fixed or other), and variables with values from 0 to 10 . In this last case, employees were asked to put a value (from $0=$ none) to 10 (maximum) on the questions posed, which were of the type "the firm offers information about the organization" or " value from 0 to 10 the heating condition of your workplace". In order to reduce the number of variables to use in the analysis, some new variables were created, according to the job dimension they belong to. In that case, Cronbach's alfa is provided. This is the case for example of physical workplace conditions, which is generated out of six original variables (air conditioning, heating, ventilation, noise, lighting and physical space in the workplace). Sample descriptive show that remuneration is fixed for most employees $(82.2 \%)$, and they do not participate in profits $(81 \%)$. Around half of employees receive training; employees on average receive relatively high information concerning the organisation and the company goals (average value 7.08). However, only $17.3 \%$ work in team. Workplace conditions are not bad: risk levels are quite low on average (3.53) and physical conditions are not very good but neither very bad, with an average of 6.69, with air conditioning and noise having the poorest values. Finally, the job dimension "work and life balance" is valued relatively well, since average values of the included items (prolonging working times and difficulty getting leave from work) are not higher than 3.5 .

[Table 1 around here please]

As in Celma et al. (2014), the analysis starts with a clustering of employees, where the HRM practices are the clustering variables. The aim here was to obtain homogeneous groups of workers which differed as much as possible from other groups or clusters 
regarding job quality. Previous to the clustering, qualitative variables were subject to a Multiple Correspondence Analysis (MCA). In this way, they were converted into a quantitative variable and hence could be included in the cluster analysis. Next, a multinomial logit analysis was regressed, where dependent variables are the clusters obtained previously. Explanatory variables are the characteristics of the firms (economic sector, company size and type of industry), of the employees (education level, gender, age, and birthplace) and the job (professional category, seniority in the firm, monthly salary and type of contract). A set of dummy variables for the year (from 2006 to 2010) was also included as explanatory variables.

\section{Results}

MCA was used to convert the following qualitative variables into quantitative ones: type of remuneration (fixed or variable), participation in profit sharing (yes/no), the firm provide training (yes/no), working in a team (yes/no). MCA seeks interdependencies between qualitative variables without a priori assuming causality between them. One dimension from the MCA is considered and included in the cluster analysis; it explains $82 \%$ of corrected inertia. Positive values indicate that the employee receives training, participates in profits (profit sharing), receives variable remuneration and works in team ${ }^{2}$. Next, a cluster analysis of the first ACM dimension and the quantitative variables (those in Table 2) was carried out. Prior to it, an analysis of atypical values, asymmetry and correlation between variables was done. Atypical values can modify the result of the cluster analysis and produce unitary clusters. The variable 'number of social benefits' was transformed by applying a square root with the aim of reducing asymmetry and eliminating atypical values. The rest of the variables were left untouched. In the cluster analysis the demands of normality, linearity and homoskedasticity were of little importance, given that it is not a statistical inference technique as such. Having said that, a check was made that the variables were not correlated and that the number of variables was not high (seven in our case). Furthermore, as the variables were measured in different units, they were standardised in order that it did not affect the weightings in the measure of similarity and/or distance used to establish the groups. For the selection of variables to be included in the cluster analysis, groupings were made to reduce the number of variables

\footnotetext{
${ }^{2}$ Details of the MCA will be provided on request.
} 
and categories. The groupings of variables were subject to reliability analyses, which gave Crombach's alpha coefficient values higher than 0.75 as shown in table 1 (they are degree of knowledge about the company, evaluation of environmental conditions and the difficulty in getting permission for family-related leave).

Clustering was carried out in two stages: first Ward's method was applied to the hierarchical clustering to obtain the initial centres, which were then used in the K-means clustering method to fine tune the result. With Ward's method 4 and 3 groups appeared as reasonable results. The 10-group through to the 5-group solutions were eliminated as they included a group with a frequency below 10\%. We thus selected the solutions with 4 and 3 groups for interpretation and we found that the two groups which were merged from the 4-group to the 3-group solution did not have worthwhile conceptual differences. In the second stage we applied the K-means clustering method to refine the final 3-group solution. Table 2 and Figure 1 show the mean value of the clustering variables for each group in the final K-means 3-group solution. These values are comparable because all the variables are standardized. The final column in Table 2 records the percentages of explained variance by the clustering. Low values of a dimension indicate low job quality in that dimension, and higher values higher quality. For example, a value of -0.41 of risk level (cluster 2) indicates higher risk levels (lower job quality) than a value of 0.78 (cluster 3)

[Please insert Table 2 around here]

[Please insert Figure 1 around here]

It is noticeable that clusters have a fairly equally distributed number of employees (cluster sizes). In Cluster 1, most variables have negative mean values; it groups employees with the lowest job quality in most of the quality dimensions. Employees in this group do not work in team, do not receive training, social benefits and little internal information about the company. Furthermore, their level of job safety is among the lowest, physical working conditions are the poorest among employees and they are also the ones facing the greatest difficulty in getting leave permits. Cluster 2 can be labelled as the 'job quality for involvement', as employees in this cluster receive labour practices which the HRM literature associates with employee involvement and high performance. It is comprised 
of employees with the highest scores in the ACM dimension, which includes working in team, participation in profits, mixed remuneration and receiving training. They also receive internal information about the company and are the ones who receive more social benefits. However, the risk level of their jobs is relatively high, their physical workplace conditions are relatively mediocre and their working day is often prolonged; but they do not experience great difficulties in getting job leaves. Cluster 3 is the one where mean values of nearly all the job quality dimensions are positive, and have in general, the highest job quality. It includes those employees who are in an intermediate position between Cluster 1 and Cluster 2, in terms of profit sharing, receiving variable remuneration, working in teams, and training and social benefits received. However, employees in this group are the ones with better job conditions related to health and safety at work: they have the lowest risk levels and the best physical workplace conditions. Moreover, they are the ones who enjoy higher CSR in the job-life balance dimension: their working day is not prolonged and they have no difficulty in getting leave. This group is distinguished, therefore, by employees being subject to labour practices that are principally oriented towards the job-life-family balance dimension of job quality and also towards the health and security at work dimension; and also the "job quality for involvement" dimension is not the worst.

Tables 3 and 4 show the result of the estimation of a multinomial logit model in which the dependent variables are the three clusters and the explanatory variables are categorical; they encompass personal characteristics, job characteristics and characteristics of the firms where the employee works, as well as a temporal variable that reflects the year (2006-2010). Years 2006 and 2007 were prior to the crisis, and the years 2008 to 2010 were in the middle of the crisis. The multinomial logit analysis takes Cluster 1 , the low job quality cluster, as the reference. Therefore, the parameter estimates indicate the probability ratio with respect to that cluster. The last category of all explanatory variables is the reference category and implicitly has an odds ratio equal to 1 . Whenever the estimated odds-ratio $(\mathrm{e} \beta$ ) is $>1$, it increases the odds of belonging to the cluster of analysis ( 2 or 3 ) instead of Cluster 1 , and compared to the reference category of the variable. Tables 3 and 4 include p-values of Wald's test, odds rations (e $\beta)$ and their lower and upper confidence limits (95\%).

(Please, insert Tables 3 and 4 here) 
The size of the company and being a private or public sector company do not seem to affect that the employee receives labour practices in the job-life-family balance dimension of job quality and in the health and security at work dimension (Cluster 3). However, the probability of employees receiving "high involvement practices" (Cluster 2 ) increases when working for large companies and public sector employers. The type of industry also seems relevant: firms operating in the service sector are associated with better job quality (Clusters 2 and 3) than those in the industry and primary sectors. Employee's characteristics and also job-related characteristics seem to have an effect. While older employees have a higher probability of receiving Cluster 3 type of job quality practices, youngest employees have a higher probability of receiving Cluster 2 "high involvement" practices. While there is no gender difference for cluster 2, being a woman increases the probability of belonging to Cluster 3 . The probability of receiving Cluster 2 and 3 practices is significantly higher for employees that have a permanent contract, high salaries, are in management positions, have been with the firm longest, have university level education and are Spanish. Finally, the lowest job quality (Cluster 1) is associated to employees who are middle-aged, to immigrants, to those who do not have university studies, have temporary contracts, and to employees who work in the primary or secondary sectors of the economy. It is also associated to employees that had been working in the firm less than five years, do not hold a management position and do not have a high salary.

Finally, to analyse the effect of the economic crisis, we take 2010 as a reference. The year appears to be significant for Group 2 and with a positive effect in the years 2006 and 2009. In Group 3 the positive effect is in 2008 and 2009, while in 2006 the effect is negative. The probability of an employee belonging to Cluster 3 (in relation to Cluster 1, the low job quality cluster) is significantly higher in the years 2008 and 2009, when the major employment destruction was taking place. The years 2008 and 2009 where when most employment was destroyed (the number of unemployed grew 41\% in year 2008 and $83 \%$ in 2009; $9 \%$ in 2010). Therefore, the results from the logit model, coupled with the information on unemployment generation, point to the fact that the economic crisis destroyed basically employments with the lowest job quality (Cluster 1). 


\section{Conclusion and discussion}

CSR studies have focussed mainly on its external dimension. Responsible practices in the management of employees have been largely neglected by the CSR literature. CSR with employees and specifically improving the quality of working life is an important goal in the European Union strategy for sustainable development. However, the financial and economic crisis has produced a decline in some countries Government's efforts, which have been more directed towards employee generation than to raising job quality. Little evidence is available on how firms have adapted to the crisis in the management of their employees and the effects on job quality. Few studies shed light on the dimensions of job quality and types of HRM practices most affected by the crisis, and even few evidence exists that provides a map of job quality and its dimensions at a regional or country level and the effects of the crisis on that map. The present study contributes to the scarce extant research and knowledge on CSR in the management of employees, by analysing which practices are being implemented and their perception by employees, generating a "map" of CSR- HRM practices that includes all economic sectors, types of jobs and employees and firms, with the focus on the effects of the economic and financial crisis on that map, and therefore, in analysing weather HRM practices implemented by firms changed as a consequence of the crisis.

The current analysis follows the methodology in Celma et al. (2014) and expands the research to focus on the impact that the economic and financial crisis has had on the types of socially responsible practices that firms apply, on their determinants and on the map of employees according to the types and extent of CSR in the HRM practices they receive. While the previous study was only for the year 2007, and hence had a static approach, the one here includes repeated cross-sections samples, which permits the study of the evolution of CSR in HRM.

For what it refers to the first and second research questions of the article: first, has the crisis had any effect on the types of responsible human management practices most broadly implemented?; and second, has the crisis had any effect in the grouping of employees, according to the level and type of responsible practices -job quality-they receive?, results obtained here do not differ from those in Celma et al. (2014). Employees are also distributed into three groups, and with the same characteristics in terms of 
responsible HRM practices received. The first one (Cluster 1) includes employees with lower job quality, in nearly all dimensions. It is especially lower in the HRM practices oriented towards enhancing employee's performance and involvement with the firm (the firm providing information and training, employees working in team, and employees participating in firm's profits). In contrast, employees in Cluster 2 enjoy higher job quality in general, and especially in the dimensions related to the (high) performance of employees. Finally, there is a group of employees (Cluster 3) with higher levels of job quality in the HRM practices related to work-life-family balance and safety and security at work; and their levels of job quality in relation to high performance practices are between Cluster 1 and Cluster 2. Therefore, in the period 2006-2010, Spanish employees are not so much characterised by enjoying low, medium, or high levels of job quality, but by dimensions of job quality, although there is a group of employees with lower levels of job quality in most of its dimensions. It is also noticeable that employees are fairly equally distributed among these groups: around $1 / 3$ have low quality jobs, around $1 / 3$ are enjoying job quality in the "high performance" dimension, and 1/3 receive better health and safety at work and conciliation practices. Moreover, no cluster was clearly associated in the present analysis to the years of deepest crisis. Therefore, it seems that the crisis has not introduced a drastic change in the distribution of job quality among employees and the type of responsible practices they receive. As advanced by Teague and Roche (2014) and Oms and Obeso (2009), firms may have been applying short-term and ad-hoc measures to cope with the crisis, without a clear strategy that resulted in a substantial change of the type of job practices applied so far, so as to be reflected in a substantial change in the precrisis job quality distribution among employees and the observed dominant dimensions in each cluster.

However, the analysis here provides indications that the crisis having affected mostly, through higher unemployment, the "low job quality" employee (the one in Cluster 1). The probability of belonging to Cluster 3 is higher during the worst years of the crisis (2008 and 2009); and in 2009 the probability of belonging to Cluster 2 is also higher. This is in line with Díaz-Caho et al. (2016) and Green et al. (2013) who found that there was a slight increase in the health and safety dimension of job quality (Cluster 3 in our case). Given that many employees lost their jobs, those still employed may have been the ones that their personal, job and/or firm's characteristics facilitated that they were still 
employed and received responsible HRM practices (Cluster 2 and Cluster 3 types of employees).

The present analysis has also shown that employee's characteristics are relevant for the distribution and types of responsible practices received by employees. According to Bryson et al. (2016), employees in managerial positions enjoy higher quality jobs; also high -skilled workers tend to have more qualified and quality jobs (Boxall, 2003; Goos et al., 2010). Results obtained in the present study are in the same line, and are very similar to the ones in Celma et al. (2014), as it has been found that employees with university studies, and those holding a managing position and earning higher salaries, have higher probabilities of enjoying higher levels of job quality. This happened not only in the years previous to the crisis, but also in the years of deepest crisis. Also employees that have a permanent job contract enjoy higher CSR in HRM practices. In contrast, immigrants, lowcategory level employees, those with lower education levels and with non-permanent contracts are the ones that had the lowest levels of job quality. It is also noticeable that women have a significant higher probability of belonging to Cluster 3 than men; they may be more interested in jobs that offer better personal-professional life conciliation conditions. Overall, in what concerns employee's characteristics, the results obtained point out that the crisis has not changed the effects of these personal characteristics on CSR in the HRM practices that employees receive.

In relation to firm's characteristics and their effects, the main results obtained indicate that the crisis has neither changed substantially the overall pattern of firms' behaviour concerning CSR in the management of their employees. For example, the service sector was the better for employees, in terms of job quality, both before and also during the crisis. It has also been found that large firms were more oriented towards HRM practices for employee's involvement and performance, by promoting human practices that develop human skills (such as training, offering internal information about the firm and work in teams, Cluster 2). Previous evidence is not conclusive regarding the effects of the size of the company and the types of human resources management practices applied; our findings are in line with the argument that that large firms may be in better conditions and have more resources to devote to these kinds of practices (Murillo, 2008; Hsu \& Cheng, 2012) and specially in times of economic recession (Ellis \& Bastin, 2011). 
In conclusion, the results from this research point that the economic and financial crisis has not changed the pre-crisis overall map of CSR in HRM practices in Catalonia, Spain, and their determinants, at least up to the year 2010. As pointed out by Homs\& Obeso (2009) and Teague \&Roche (2014), firms may have been applying ad-hoc and short-term measures to cope with the crisis, maintaining the main HRM practices that were implementing before the crisis, without adjusting their strategies, included the HRM strategy, to face a large period of crisis and possibly the need to adapt to a new way of doing business.

With regard to the implications of the analysis, there are those related to firms' adjustments to the crisis in a longer term. The effects of adjustments, if any, could be observed and analysed with data for years after 2010. These data were unavailable at the moment of doing this article since the Spanish government ceased the Quality of Life Survey in 2010. Firms would have had more time to adapt to the crisis and longer-term adjustments could be picked up. Results from the present study point out that the function of HRM in firms' management during the crisis has been kept at an operational level (McDonnell \& Burgess, 2013), helping the labour cost-adjustments and maintaining the current state of things, instead of being raised to a strategic function and play a major role in firm's adjustment to the crisis. Hopefully, with time, firms took greater consciousness of the crisis and of it being there for a long period of time. They might have tried to compensate the negative effects on competitiveness of the cost-containment measures implemented, with what Shen and D'Netto (2012) call effective strategies in the HRM sphere, such as those directed towards increasing employee's involvement.

The result that the main characteristics of CSR in HRM practices in Catalonia, Spain, have not changed during the crisis is compatible with previous evidence of a reduction on job quality, especially when macro labour indicators are included in the analysis (DiazCaho et al., 2016; European Comission, 2011). Most cost-containment measures applied by firms, in the short term, such as dismissals, wages freezes and cuts, and the generation of new jobs, which were part-time and with non-permanent contracts, were not included in the present analysis. The reduction in job quality during the crisis requires firms to further concentrate not only on employee's involvement practices, but also in HRM strategies and practices that improve CSR-job quality in all spheres; and to pay special attention to increasing the job quality of those worst-off in terms of CSR in HRM 
practices. CSR-job quality positively contributes to firms' competitiveness but also to country's sustainable grow (European Commission, 2011). Therefore, also public policies should devote more resources and efforts to raise job quality-CSR in the management of employees, with an eye to the future.

As for the limitations of the study, further analysis on the effects of the crisis would benefit from asking firms about CSR in their HRM, and especially what changes, if any, have firms applied as a consequence of the crisis and the reasons for so doing. A parallel survey to their employees would offer information from two of the main stakeholders in the job relationship and interested groups in job quality, employees and firms. Future analysis that aims to providing more detailed information than the one in this article should differentiate between economic sectors within each of the three broad economic sectors here analysed. This may be especially relevant in the service sector, which is the main sector in Catalonia and has appeared in this research to be the better, for job quality. However, it is highly heterogeneous, including personal services, such as health, education and social services, but also hospitality, retail and transport, banking and insurance, etc. which can have substantial differences in the various dimensions of job quality. Last but not least, among the many ways to generate valuable information that complements this research, is working with more detailed types of jobs and include HRM practices which allow to measure items of job quality which have not been measured here, such as fairness in remuneration.

Replications of this study in other region and countries, could offer information on the similarities and differences in the job-quality map of employees in regions which may belong to a same political space (such as a country, or countries within the European Union), but may differ greatly in job quality-CSR in the management of employees and its distribution, that require specific and various actions. 


\section{References}

Amossé, T., Bryson, A., Petit, H. 2016. How did workplaces respond to recession? in Comparative workplace employment relations, Amossé, T. Bryson, A., Forth, J., Petit, H. (Eds.). Palgrave MacMillan; London; 211-239.

Appelbaum, E., Bailey T., Berg P., Kalleberg A.L., 2000. Manufacturing Advantage: Why High-Performance Work Systems Pay Off. Ithaca Cornell University Press.

Aragón J., Rocha F. 2004. La responsabilidad social empresarial en España: una aproximación desde la perspectiva laboral. Colección Informes y estudios. Serie General, 16. Ministerio de Trabajo y Asuntos Sociales: Madrid.

Boxall P. 2003. HR strategy and competitive advantage in the service sector. Human Resource Management Journal 133: 5-20.

Bryson,A., Erthel, C. Salibekyan, Z. 2016. Job quality, in Comparative workplace employment relations, Amossé, T. Bryson, A., Forth, J., Petit, H. (Eds.), Palgrave MacMillan: London; 179-209.

Cascio, W.F., Boudreau, J.W. 2012. Short Introduction to Strategic Human Resource Management, Cambridge University Press: Cambridge.

Celma D, Martinez-Garcia E., Coenders G. 2014. Corporate Social Responsibility in Human Resource Management: An analysis of common practices and their determinants in Spain, Corporate Social Responsibility and Environmental Management 21: 82-99.

Danford, A., Richardson, M., Stewart, P., Tailby, S., Upchurch, M. 2008. Partnership, high performance work systems and quality of working life. New Technology Work and Employment 23(3), 151-66.

Díaz-Caho A., Ficapal-Cusí P., Torrent-Sellens J. 2016. Economic crisis and job quality in Spain: A multi-dimensional and micro-data empirical approach. Social Indicators Research 125 (2): 613-633.

Díaz, B. García R., Baraibar, E. 2016. Key Corporate Social Responsibility Initiatives: An Empirical Evidence from Spain, in Key initiatives in CSR, Springer International Publishing; 71-102.

Dobers P. 2009. CSR Management and Methods. Corporate Social Responsibility and Environmental Management, 17:63-69.

Ellis L., Bastin, C. 2011. Corporate Social Responsibility in times of recession: changing discourses and implications for policy and practice. Corporate Social Responsibility and Environmental Management 18: 294-305. 
European Commission. 2001. Employment and social policies: a framework for investing in quality. COM 2001, 366 final. European Comission: Brussels.

European Comission 2011. Estrategia renovada de la UE para 2011-2014 sobre la responsabilidad social de las empresas. COM (2011) 681 final. European Comission: Bruselas.

Gallie D.,Zhou Y., Felstead A., Green, F. 2012. Teamwork, skill development and employee welfare. British Journal of Industrial Relations 50 (1): 23-46.

Gamero C. 2009. Valoración de las características de los empleos por nativos e inmigrantes: el enfoque de la satisfacción con la vida. Principios: estudios de economía política 14: 93-111.

García P, De la Torre C, Fuertes A. 2007. El desafío empresarial de la gestión de la responsabilidad social corporativa: un enfoque sectorial. Avanzando hacia una empresa socialmente responsable, Vol 1. IESE Business School: Madrid.

Goos, M., Manning, A., Salomons, A. 2010. Explaining job polarization in Europe: The roles of technology, globalization and institutions. CEP Discussion Paper No. 1026. London School of Economics: London.

Green, F., Mostafa, T. 2012. Trends in job quality in Europe. A report based on the fifth European working conditions survey, Publications Office of the Europen Union: Luxemburg.

Green, F., Mostafa, T., Parent-Thirion, A., Vermeylen, G., Van Houten, G., Biletta, I., Yrjanainen, M. 2013. Is job quality becoming more unequal?. Industrial and Labor Relations Review 66 (4): 753-784.

Greenan, N., Kalugina, E. Walkowiak, E. 2014. Has the quality of working life improved in the EU-15 between 1995 and 2005?. Industrial and Corporate Change 23 (2): 399-428.

Guest, D.E. 2002. Human resource management, corporate performance and employee wellbeing: building the worker into HRM. Journal of Industrial Relations 44 (3): 335358.

Guest D. E. 2011. 'Human resource management and performance: still searching for some answers'. Human Resource Management Journal 21 (1): 3-13.

Gunnigle P, Lavelle J., Monaghan S. 2013. Weathering the storm? Multinational companies and human resource management through the global financial crisis. International Journal of Manpower 34 (3): 214-231. 
Homs O., Obeso C. 2009. Impactos de la crisis en las relaciones laborales en España. La Primera Crisis Global: Procesos, Consecuencias, Medidas. ICE Septiembre-Octubre 850: 89-108.

Hofstede G. 1991. Culture and organizations, Sage: Beverly Hills, CA.

Hsu, JL., Cheng MC. 2012. What prompts small and medium enterprises to engage in corporate social responsibility? A study from Taiwan. Corporate Social Responsibility and Environmental Management 19 (5): 288-305.

Idson T., Oi W. 1999. Workers are more productive in large firms. American Economic Review, Papers and Proceedings 89: 104-108.

ILO (International Labour Organization). 2012. Decent Work Indicators: concepts and definitions; ILO Manual, First Edition. ILO: Geneva.

Instituto de Estudios Laborales 2006. Informe Cranfield ESADE 06. Gestión Estratégica de Recursos Humanos 2004-2005. ESADE: Barcelona.

Izquierdo M., Lacuesta A. 2010. "Desarrollos recientes en el mercado de trabajo", Papeles de Economía Española 124: 2-16.

Laborda A. 2011. El mercado laboral español: Situación y perspectivas a corto plazo", Cuadernos de Mercado de Trabajo 7: 22-39.

Lahera A. 2006. "Diseñando el futuro del trabajo: ¿avanzando hacia un trabajo decente y un empleo de calidad o hacia un trabajo degradado y un empleo precarizado?". In $L a$ exclusión social y el estado de bienestar en España, F. Vidal Fernández (Ed). Icaria: Barcelona; 365-405.

La Caixa. 2013. Estudios y Análisis Económicos. La Caixa: Barcelona.

Mankelow G. 2008. Social responsibility paradox of small business human resource management practices. International Journal of Human Resource Management 19: 2171-2181.

McDonnell, A., Burgess J. 2013. The impact of the global financial crisis on managing employees", International Journal of Manpower 34 (3): 184 - 197.

Media Responsable. 2007. RRHH y RSE. June 6. Media Responsable: Premià de Mar.

Merino MC, Somarriba N, Negro AM. 2012. Un análisis dinámico de la calidad del trabajo en España. Los efectos de la crisis económica. Estudios de Economía Aplicada 30 (1): 261-282.

Mora, T., Ferrer-i-Carbonell, A. 2009. The job satisfaction gender gap among young recent university graduates: evidence from Catalonia, Journal of Socio-Economics 38: 581-589. 
Muñoz del Bustillo, R., Fernández-Macías, E., Antón, J.I., Esteve, F. 2011. Measuring more than money- The Social Economics of job quality, Edward Elgar: Cheltenham.

Murillo D. 2008. La responsabilitat social de l'empresa a les PIMES de Catalunya. Anàlisi del discurs empresarial. Tesis doctoral de la Facultad de Ciencias Económicas y Empresariales de la Universidad de Barcelona: Barcelona.

OECD 2013. How's life?2013: Measuring Well-being, OECD Publishing: Paris.

OECD. 2014. Employment Outlook 2014. OECD Publishing: Paris.

Olcese A. 2013. Informe sobre la responsabilidad social de la empresa en España. Una propuesta para Europa. Comisión Europea: París.

Prieto C, Arnal M, Caprile M., Potrony J. 2009. La calidad del empleo en España: una aproximación teórica y empírica. Ministerio de Trabajo e Inmigración: Madrid.

Prosser, T. 2016. Dualization or liberalization? Investigating precarious work in eight European countries. Work Employment \& Society 30 (6): 949-965.

Ryan, M., Slevin, G. 2012. 'Boston or Berlin: how has Ireland's labour market responded to the Great Recession'. Quarterly Bulletin of the Central Bank, Quarter 1: $18-19$.

Roche, W., Teague, P., Coughlan, A., Fahy, M. 2011. Human Resources in the Recession: Managing and Representing People at Work in Ireland, Report to the Labour Relations Commission Ireland, Dublin.

Shen J., D'Netto, B. 2012. Impact of the 2007-09 global economic crisis on human resource management among Chinese export-oriented enterprises. Asia Pacific Business Review 18 (1): 45-64.

Sheppeck MA, Militello J. 2000. Strategic HR configurations and organizational performance. Human Resource Management 391: 5-16.

Singh, T., Srivastav, S.K. 2012. QWL and Organization Efficiency: a Proposed Framework. Journal of Strategic Human Resource Management 1(1): 1- 13.

Smith A, Hayton G. 1999. What drives enterprise training? Evidence from Australia. International Journal of Human Resource Management 102: 251-272.

Social Accountability International. 2001. Social Accountability 8000 International Standards. (SAI, New York).

Somarriba N, Merino M.C., Ramos, G., Negro A. 2010. La calidad del trabajo en la Unión Europea. Estudios de Economía Aplicada 28 (3): 1-22. 
Steurer, R., Martinuzzi, A. Margula, S. 2012. Public policies on CSR in Europe: Themes, instruments and regional differences. Corporate Social Responsibility and environmental management 19 (4): 206-227.

Teague, P., Roche, W.K. 2014. Recessionary bundles: HR practices in the Irish economic crisis, Human Resource Management Journal 24 (2): 176-192.

Terpstra D, Rozell E. 1993. The relationship of staffing practices to organizational level measures of performance. Personnel Psychology 46: 27-48.

United Nations Organization (1999). Global Compact. Principles of Global Compact. United Nations Organization, New York. 


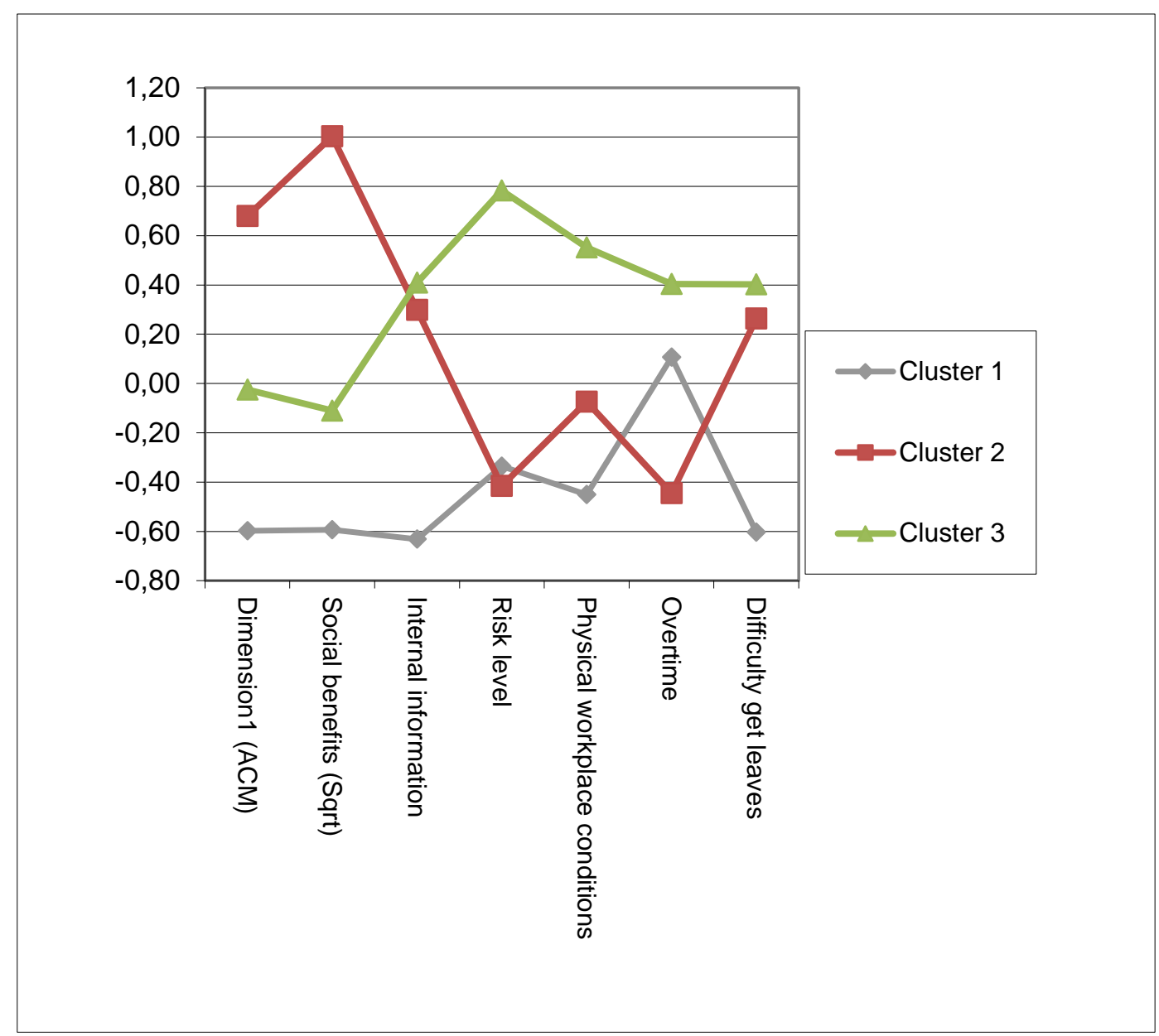

Figure 1. Cluster profile chart K-means 
Average

VARIABLES

(Standard Deviation) Percentage

$\mathrm{n}$

\section{REMUNERATION}

Type of remuneration

Fixed

82.2

7332

Variable or mixed

Participation in profits

Yes

No

TRAINING

Company offers training

$$
\text { Yes }
$$

No

INFORMATION AND INTERNAL COMUNICATION

(Cronbach's $\alpha=0,84)(0=$ none; $10=$ maximum $)$

Information about organisational chart

Teamwork

Yes

No

HEALTH AND SAFETY

Risk level $(0=$ none; $10=$ very high $)$

Physical workplace conditions (summated scale)

(Cronbach's $\boldsymbol{\alpha}=0,75)(0=$ very poor; $10=$ very good $)$

Heating evaluation

Ventilation evaluation

Noise evaluation

Lighting evaluation

$8.00(1.992)$

8048

Physical space evaluation

(Cronbach's $\alpha=0,84)(0=$ none; $10=a$ lot $)$

Difficulty requesting unpaid leave

Difficulty requesting long leave 


\begin{tabular}{lcccc}
\hline & \multicolumn{3}{c}{ Cluster } & \multicolumn{2}{c}{ explained } \\
\cline { 2 - 5 } & 1 & 2 & 3 & variance \\
\hline Dimension 1 MCA (type of remuneration; participation & -0.59763 & 0.68014 & -0.02464 & 0.237 \\
in profits; training; teamwork) & & & & \\
Social benefits (square root) & -0.59416 & 1.00274 & -0.10993 & 0.623 \\
Internal information & -0.63206 & 0.29817 & 0.40882 & 0.464 \\
Risk level** & -0.3364 & -0.41536 & 0.78367 & 0.383 \\
Physical workplace conditions & -0.45074 & -0.0737 & 0.55199 & 0.378 \\
Overtime** & 0.10673 & -0.44538 & 0.40371 & 0.505 \\
Difficulty getting leave** & -0.60348 & 0.26314 & 0.40256 & 0.301 \\
Cluster size & $35,1 \%$ & $32,7 \%$ & $32,2 \%$ & \\
\hline
\end{tabular}

Table 2. Mean values for clustering variables $\mathrm{K}$-means with 3 dusters Positive sign indicates better results for the employee on all variables ** shows reverse coded variables 


\begin{tabular}{|c|c|c|c|c|}
\hline \multicolumn{5}{|c|}{ EXPLANATORY VARIABLES } \\
\hline \multirow{3}{*}{ Type of contract } & & $e \beta$ & Confidence & $($ for $\mathrm{e} \beta 95 \%)$ \\
\hline & Permanent & 1. $563 * * *$ & 1.261 & 1.938 \\
\hline & Temporary & 1.000 & 1.000 & 1.000 \\
\hline \multirow[t]{4}{*}{ Company size } & Micro & $0.211 * * *$ & 0.171 & 0.259 \\
\hline & Small & $0.340 * * *$ & 0.284 & 0.408 \\
\hline & Medium & $0.567 * * *$ & 0.47 & 0.683 \\
\hline & Large & 1.000 & 1.000 & 1.000 \\
\hline \multirow[t]{3}{*}{ Type of industry } & Primary sector / Construction & $0.609 * * *$ & 0.471 & 0.786 \\
\hline & Manufacturing & $0.620 * * *$ & 0.526 & 0.731 \\
\hline & Services & 1.000 & 1.000 & 1.000 \\
\hline \multirow[t]{3}{*}{ Age } & $<25$ & 1. $490 * *$ & 1. 059 & 2. 094 \\
\hline & $26-55$ & 1.074 & 0.891 & 1. 295 \\
\hline & $>55$ & 1.000 & 1.000 & 1.000 \\
\hline \multirow[t]{2}{*}{ Gender } & Man & 0.953 & 0.82 & 1. 107 \\
\hline & Woman & 1.000 & 1.000 & 1.000 \\
\hline \multirow[t]{3}{*}{ Level of education } & No studies / Primary educatic & $0.254 * * *$ & 0.2 & 0.323 \\
\hline & Secondary education & $0.446 * * *$ & 0.373 & 0.534 \\
\hline & University education & 1.000 & 1.000 & 1.000 \\
\hline \multirow[t]{3}{*}{ Birthplace } & Catalonia & 2. $614 * * *$ & 2. 018 & 3.386 \\
\hline & Rest of Spain & 2. $070 * * *$ & 1. 538 & 2.786 \\
\hline & Immigrants & 1.000 & 1.000 & 1.000 \\
\hline \multirow[t]{2}{*}{ Professional category } & Staff & $0.521 * * *$ & 0.436 & 0.623 \\
\hline & Manager & 1.000 & 1.000 & 1.000 \\
\hline \multirow[t]{3}{*}{ Seniority in the firm } & $<1$ year & $0.667 * *$ & 0.527 & 0.844 \\
\hline & $1-5$ years & $0.744 * *$ & 0.625 & 0.885 \\
\hline & $>5$ years & 1.000 & 1.000 & 1.000 \\
\hline \multirow[t]{3}{*}{ Monthly salary } & $<1.200 €$ & $0.184 * * *$ & 0.133 & 0.254 \\
\hline & $1.201-2.100 €$ & $0.418^{* * *}$ & 0.308 & 0.566 \\
\hline & $>2.100 €$ & 1.000 & 1.000 & 1.000 \\
\hline \multirow[t]{2}{*}{ Public or Private sector } & Public & $1.226 * *$ & 1. 041 & 1. 444 \\
\hline & Private & 1.000 & 1.000 & 1.000 \\
\hline \multirow[t]{5}{*}{ Year } & 2006 & 1. $491 * * *$ & 1. 201 & 1.852 \\
\hline & 2007 & 0.936 & 0.745 & 1.175 \\
\hline & 2008 & 1.153 & 0.92 & 1.445 \\
\hline & 2009 & 1. $693 * * *$ & 1. 344 & 2. 133 \\
\hline & 2010 & 1,000 & 1,000 & 1,000 \\
\hline
\end{tabular}

Table 3. Multinomial logit model duster 2

$* * * \mathrm{p}<0,01 * * \mathrm{p}<0,05 * \mathrm{p}<0,10$ Wald's test significance 


\begin{tabular}{|c|c|c|c|c|}
\hline \multicolumn{5}{|c|}{ EXPLANATORY VARIABLE } \\
\hline & & $e \beta$ & Confidence & $1($ for $\mathrm{e} \beta 95 \%)$ \\
\hline \multirow[t]{2}{*}{ Type of contract } & Permanent & 1. $666 * * *$ & 1.378 & 2.015 \\
\hline & Temporary & 1. 000 & 1. 000 & 1. 000 \\
\hline \multirow[t]{4}{*}{ Company size } & Micro & 1. 101 & 0.929 & 1. 305 \\
\hline & Small & 0.992 & 0.837 & 1. 177 \\
\hline & Medium & 0.955 & 0.79 & 1. 154 \\
\hline & Large & 1. 000 & 1. 000 & 1. 000 \\
\hline \multirow[t]{3}{*}{ Type of industry } & Primary sector / Cons & $0.525 * * *$ & 0.415 & 0.664 \\
\hline & Manufacturing & $0.671 * * *$ & 0.576 & 0.781 \\
\hline & Services & 1.000 & 1. 000 & 1.000 \\
\hline \multirow[t]{3}{*}{ Age } & $<25$ & 0.836 & 0.614 & 1. 139 \\
\hline & $26-55$ & $0.826 * *$ & 0.694 & 0.983 \\
\hline & $>55$ & 1.000 & 1. 000 & 1. 000 \\
\hline \multirow[t]{2}{*}{ Gender } & Man & $0.571 * * *$ & 0.498 & 0.656 \\
\hline & Woman & 1. 000 & 1. 000 & 1. 000 \\
\hline \multirow[t]{3}{*}{ Level of education } & No studies / Primary & $0.327 * * *$ & 0.262 & 0.407 \\
\hline & Secondary education & $0.572 * * *$ & 0.479 & 0.682 \\
\hline & University education & 1. 000 & 1. 000 & 1. 000 \\
\hline \multirow[t]{3}{*}{ Birthplace } & Catalonia & 1. $816^{* * *}$ & 1. 488 & 2. 217 \\
\hline & Rest of Spain & 1. $590 * * *$ & 1.25 & 2. 022 \\
\hline & Immigrants & 1. 000 & 1. 000 & 1. 000 \\
\hline \multirow[t]{2}{*}{ Professional category } & Staff & $0.603 * * *$ & 0.505 & 0.721 \\
\hline & Manager & 1. 000 & 1. 000 & 1.000 \\
\hline \multirow[t]{3}{*}{ Seniority in the firm } & $<1$ year & 0.937 & 0.765 & 1. 149 \\
\hline & $1-5$ years & $0.793 * * *$ & 0.677 & 0.929 \\
\hline & $>5$ years & 1. 000 & 1. 000 & 1. 000 \\
\hline \multirow[t]{3}{*}{ Monthly salary } & $<1.200 €$ & $0.489 * * *$ & 0.349 & 0.683 \\
\hline & $1.201-2.100 €$ & $0.546 * * *$ & 0.395 & 0.756 \\
\hline & $>2.100 €$ & 1. 000 & 1. 000 & 1. 000 \\
\hline \multirow[t]{2}{*}{ Public or Private sector } & Public & 1.007 & 0.861 & 1. 178 \\
\hline & Private & 1. 000 & 1. 000 & 1.000 \\
\hline \multirow[t]{5}{*}{ Year } & 2006 & $0.814 * *$ & 0.665 & 0.997 \\
\hline & 2007 & 0.920 & 0.75 & 1. 129 \\
\hline & 2008 & 1. $255 * *$ & 1. 026 & 1. 535 \\
\hline & 2009 & 1. $661 * * *$ & 1. 347 & 2. 046 \\
\hline & 2010 & 1. 000 & 1. 000 & 1. 000 \\
\hline
\end{tabular}

Table 4. Multinomial logit model duster 3

*** $\mathrm{p}<0,01 * * \mathrm{p}<0,05 * \mathrm{p}<0,10$ Wald's test significance 